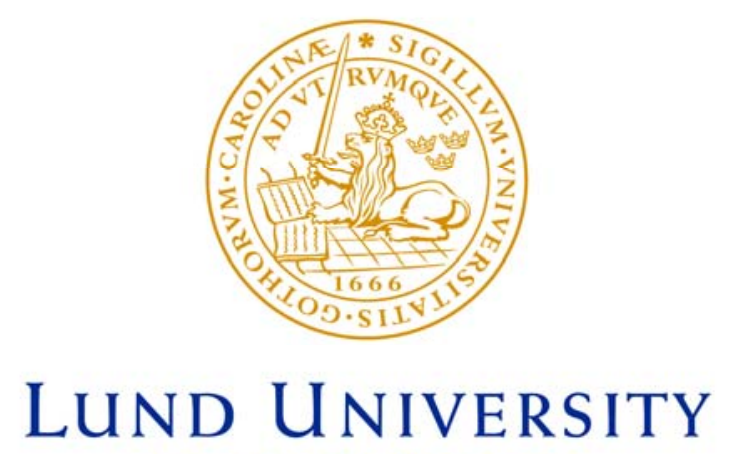

Faculty of Medicine

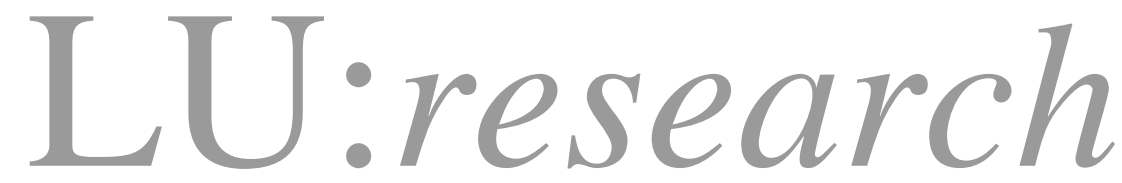

Institutional Repository of Lund University

This is an author produced version of a paper published in Blood coagulation \& fibrinolysis: an international journal in haemostasis and thrombosis. This paper has been peerreviewed but does not include the final publisher proofcorrections or journal pagination.

Citation for the published paper:

Engstrom, Martin and Schott, Ulf and Reinstrup, Peter.

"Ethanol impairs coagulation and fibrinolysis in whole blood: a study performed with rotational thromboelastometry"

Blood coagulation \& fibrinolysis: an international journal in haemostasis and thrombosis, 2006, Vol: 17, Issue: 8, pp. 661-5.

http://dx.doi.org/10.1097/MBC.0b013e32801010b7

Access to the published version may require journal subscription.

Published with permission from: Wolters Kluwer 


\title{
Ethanol impairs coagulation and fibrinolysis in whole blood - A study performed with rotational thromboelastometry
}

\author{
Martin Engström MD, PhD, Ulf Schött MD, PhD, Peter Reinstrup MD, \\ PhD
}

\section{Corresponding author}

Martin Engström, MD, PhD

Department of Anaesthesia and Intensive Care

Lund University Hospital

22185 Lund

Sweden

Phone: +4646171949

Fax: +4646176050

E-mail: martin.engstrom@med.lu.se

\section{Other authors}

Ulf Schött, MD, PhD

Department of Anaesthesia and Intensive Care, Halmstad County Hospital, Halmstad, Sweden

E-mail: ulf.schott@1thalland.se

Peter Reinstrup MD, PhD

Department of Anaesthesia and Intensive Care, Lund University Hospital, Lund, Sweden E-mail: peter.reinstrup@med.lu.se

\section{Running title: Ethanol impairs the coagulation system}

This study was supported by a research grant from the Laerdal Foundation for Acute Medicine.

\section{Word count}

Abstract: 202

Main text: 1531 


\section{ABSTRACT}

Objective: The objective of the study was to study the effects of ethanol on the coagulation and the fibrinolysis in whole blood. Methods: Blood samples from healthy volunteers were analysed before and after in vitro addition of ethanol in order to achieve ethanol concentrations of $0 \%, 1 \%$, $2 \%$ and $4 \%$ respectively $(0,22,44$ and $88 \mathrm{mmol} / \mathrm{l})$. Coagulation and fibrinolysis were then assessed using rotational thromboelastometry. Results: We found that increasing ethanol levels increasingly impaired coagulation as evaluated with rotational thromboelastometry with a maximum prolongation of Clot Formation Time of $118 \%$ at an ethanol level of $4 \%$ o $(p<0.000001)$. We also found a very strong impairment of fibrinolysis already at an ethanol level of 1\%o. Conclusions: This is the first study assessing the effects of ethanol on coagulation and fibrinolysis in a whole blood model. The impairment of coagulation is similar in nature to the impairment found in patients suffering from hypothermia. The impairment is at a level that may be of clinical importance, e.g. in patients suffering from trauma. The inhibition of fibrinolysis is obvious already at an ethanol level of $1 \%$ and it may be a contributing factor to the increased amount of coronary and cerebrovascular ischemic events after binge drinking.

Keywords: alcohol, coagulation, ethanol, fibrinolysis, ROTEM, thromboelastometry, 


\section{INTRODUCTION}

The use and abuse of alcoholic beverages are common features in trauma patients $[1,2]$. More than $30 \%$ of injured drivers admitted to a trauma centre have detectable alcohol levels in their blood [3].

It is in our clinical experience common that patients suffering from traumatic brain injuries (TBI) have pronounced progression of their intracranial hemorrhages, e.g. contusions. It is also known that impairment of the coagulation of different origins, e.g. NSAID treatment or consumption coagulopathy, is associated with worse outcome in TBI patients[4-6].

It is in our clinical experience common that patients with high ethanol levels suffering from TBI have pronounced progression of their intracranial hemorrhagic complication. Effects on the coagulation and fibrinolytic systems by increased ethanol levels have been previously described. However, these studies have in general been performed on components of blood, rather than on whole blood, and the effects reported are not in agreement. Several studies have found an alcohol induced impairment of the primary hemostasis, whereas the humoral coagulation factors and the fibrinolytic system were unaffected [7-9]. El-Sayed et al [10] corroborated these results on the humoral coagulation factors and the fibrinolysis, but others have found an acute impairment of the fibrinolytic system by increased ethanol levels [11, 12]. One study also described an increase in fibrinolytic activity after alcohol withdrawal in chronic alcoholics[13]. Another study found somewhat contrasting results indicating an increase in platelet aggregation after binge drinking[14].

These observations have lead us to perform a study where we have evaluated the effects of increased blood ethanol levels on the hemostatic and fibrinolytic systems. We have used 
rotational thromboelastometry (ROTEM) to perform the studies. ROTEM is a whole blood method assessing both hemostasis (humoral coagulation and platelet activity) and fibrinolysis in the same analysis. ROTEM is considered a better predictor of clinical bleeding tendency than other coagulation tests[15-17].

\section{MATERIAL AND METHODS}

The study was approved by the ethics committee of Lund University Hospital, Sweden. Six healthy volunteers gave informed consent to participate in the study.

\section{Blood sampling}

An indwelling brachial venous catheter was used for blood sampling. Four blood samples were taken from each participant. Each blood sample consisted of $4 \mathrm{ml}$ of blood collected in a siliconated test tube without additives. Before each sampling the initial blood drawn was discarded. One blood sample was analysed without addition of any ethanol. The other three were analysed after addition of 5, 10 and $20 \mu \mathrm{L}$ of $96 \%$ pure ethanol resulting in ethanol concentrations of $1 \%$, $2 \%$ and $4 \%$ respectively.

\section{Thromboelastometry}

A rotating thromboelastometer (ROTEM) analyser (Pentapharm ${ }^{\circledR}$ GMBH, Munich, Germany) was used. All analyses were performed at $37^{\circ} \mathrm{C}$ and the analyses were performed on whole blood. Coagulation was activated with $20 \mu \mathrm{L}$ of a tissue factor (TF) containing activator according to the EXTEG procedure described by the manufacturer. Four parameters were measured. The first parameter was Clotting Time (CT) measuring the time to initiation of clot formation and reflecting the initiation of the coagulation. Clot Formation Time (CFT) measuring the rate of increasing clot firmness once the clotting has started, reflecting platelet 
activity and rate of fibrinogen to fibrin conversion, was also measured. Alpha Angle also reflects the rate of clot strengthening after clotting is initiated. Maximum Clot Firmness (MCF) describing the maximum strength of the clot is another parameter measured that is primarily affected by the platelet count. Lysis Index after 60 minutes (LI60), describing the fibrinolytic activity as the clot firmness 60 minutes after initiation of the analysis in percent of the MCF, was the final parameter measured (Figure 1).

\section{Analyses}

The blood was mixed with ethanol immediately after the blood was drawn. The ROTEM analysis was started exactly 90 seconds after the blood was drawn by adding $320 \mu \mathrm{L}$ of blood to a cuvette already containing $20 \mu \mathrm{L}$ of $\mathrm{TF}$-containing activator according to standard ROTEM Procedure.

\section{Statistics}

Box plots show medians with the box representing $25^{\text {th }}$ to $75^{\text {th }}$ percentiles and the whiskers representing the range. All statistical analyses have been performed with non-parametric statistical methods. The Wilcoxon rank order test was used to study the effects on fibrinolysis. The Spearman rank order test was used for correlation analysis of the effects on the coagulation system. A p-value of less than 0.05 was considered to be statistically significant.

\section{RESULTS}

No participant withdrew from the study and the blood sampling was performed uneventfully. Increasing the ethanol concentrations progressively impaired the coagulation system. 
The impairment was seen in CFT $(\mathrm{p}<0.000001, \mathrm{r}=0.91)$ and alpha angle $(\mathrm{p}=0.000001, \mathrm{r}=0.88)$

(Figure 2). The CFT was prolonged by $34 \%$ at an ethanol level of $1 \%$ and by $118 \%$ at an ethanol level of 4\%. There were no significant changes to CT and MCF.

The fibrinolysis was also significantly impaired with a virtually total elimination of fibrinolytic activity $(\mathrm{p}=0.03)$ already at an ethanol level of $1 \%$. Median LI60 was $90 \%$ when there was no ethanol added to the blood (Figure 3A). At an ethanol level of $1 \%$ the median LI60 was 97\% (Figure 3B). At higher ethanol levels the LI60 was 98\%.

\section{DISCUSSION}

ROTEM is gaining increasing popularity as a coagulation monitoring tool as the technique becomes more user-friendly and robust. It seems to be more sensitive and specific than routine coagulation tests in detecting defects of the coagulation system [16, 18-22]. It has also been used as a tool for detection of coagulation defects in patients undergoing cardiac and liver surgery $[15,23-26]$. ROTEM measures the rate of clot formation and clot strengthening after coagulation. The result is displayed as a graph where the clot strength is found on the $\mathrm{Y}$ axis and time is displayed on the $\mathrm{X}$ axis (Figure 1).

In this study we have found that increased ethanol levels correlated to an impairment of the in vitro coagulation. The impairment was seen as a prolongation of CFT and a lowering of the alpha angle. These parameters primarily reflect the fibrinogen to fibrin conversion and the platelet activity, even though all parameters in some way is a reflection of thrombin generation which in turn leads to clot formation and stabilisation. There were no changes in the initiation phase or in the maximum strength of the clot. These findings may indicate that the reactions are still running, but at a lower rate. The coagulation would then be initiated at 
the correct time but run slower and the clot strength would eventually reach the same strength but at a later point in time, explaining the absence of change in $\mathrm{CT}$ and MCF.

Previous studies investigating effects of acidosis and of hypothermia on the coagulation system have found impairments of the coagulation very similar in nature to the effects of increased ethanol levels $[27,28]$. The effects are readily detectable already at an ethanol level of $1 \%$ and may be of importance in trauma patients. The link between impairment of the coagulation system and progression of intracranial hemorrhage in trauma patients has been well described. [29, 30]. A link between impairment of coagulation and worse outcome has also been found $[5,6]$. The finding that thrombocytopenia at admission predicts progressive hemorrhage in TBI patients indicates a correlation between the coagulation system and progressive hemorrhage [31]. Altogether, many TBI patients have multiple reasons for developing delayed hemorrhagic complications and ethanol levels may be another factor necessary to consider during management of TBI patients. Ethanol has been found to decrease collagen induced platelet aggregation and this may be a problem viewed in the light of the finding that patients on NSAIDs have a higher mortality rate after TBI[4, 32]. In our study we also found a prolongation of CFT that may be interpreted as an impairment of the platelet activity.

Another aspect of the effects of ethanol on coagulation is the impairment of fibrinolysis. An impairment has been described previously, but not in whole blood. Several different studies have addressed this issue and found somewhat conflicting results. Most studies have found an increase in fibrinolytic activity after ethanol intake. Some studies have found an upregulation of tPA expression and a decrease in PAI-1 transcription, something that would explain the increased fibrinolytic activity[33-36]. However, there are also studies having found an acute 
inhibitory effect or no effect at all of ethanol on fibrinolysis[9-11]. We found a decrease in fibrinolytic activity in this study, a finding supporting van de Wiel et al who found similar results in their study[11]. However, a weakness in our study is that we are not able detect interactions between the endothelium and components in blood that may be of importance in this process.

A possible explanation to the conflicting results regarding the effects of ethanol on fibrinolysis may be that ethanol acutely impairs fibrinolysis, but upregulates transcription

of profibrinolytic genes, e.g. tPA genes and down regulates antifibrinolytic genes, e.g. PAI-1, leading to an increase in fibrinolytic activity in the longer perspective. This would also explain the increased risk for ischemic coronary or cerebrovascular disease after binge drinking, even though moderate intake of ethanol in the longer perspective may be protective against such diseases.

\section{CONCLUSIONS}

Ethanol impairs the coagulation system and seems to inhibit fibrinolysis in the short perspective. Intoxication by ethanol may be a risk factor for increased hemorrhage in patients suffering from trauma. 


\section{REFERENCES}

1. Singleton M, Qin H, and Luan J Factors associated with higher levels of injury severity in occupants of motor vehicles that were severely damaged in traffic crashes in Kentucky, 2000-2001. Traffic Inj Prev 2004; 5: 144-50.

2. McAnally HM and Kypri K Alcohol and road safety behaviour among New Zealand tertiary students. Int J Adolesc Med Health 2004; 16: 229-37.

3. Michael Walsh J, Flegel R, Atkins R, Cangianelli LA, Cooper C, Welsh C, et al. Drug and alcohol use among drivers admitted to a Level-1 trauma center. Accid Anal Prev 2005; 37: 894-901.

4. Mina AA, Knipfer JF, Park DY, Bair HA, Howells GA, and Bendick PJ Intracranial complications of preinjury anticoagulation in trauma patients with head injury. $J$ Trauma 2002; 53: 668-72.

5. Selladurai BM, Vickneswaran M, Duraisamy S, and Atan M Coagulopathy in acute head injury--a study of its role as a prognostic indicator. Br J Neurosurg 1997; 11: $398-404$.

6. Vavilala MS, Dunbar PJ, Rivara FP, and Lam AM Coagulopathy predicts poor outcome following head injury in children less than 16 years of age. $J$ Neurosurg Anesthesiol 2001; 13: 13-8.

7. Serebruany VL, Lowry DR, Fuzailov SY, Levine DJ, O'Connor CM, and Gurbel PA Moderate alcohol consumption is associated with decreased platelet activity in patients presenting with acute myocardial infarction. J Thromb Thrombolysis 2000; 9: 229-34. 
8. Elmer O, Goransson G, and Zoucas E Impairment of primary hemostasis and platelet function after alcohol ingestion in man. Haemostasis 1984; 14: 223-8.

9. Zoucas E, Bergqvist D, Goransson G, and Bengmark S Effect of acute ethanol intoxication on primary haemostasis, coagulation factors and fibrinolytic activity. Eur Surg Res 1982; 14: 33-44.

10. el-Sayed MS, Eastland P, Lin X, and Rattu AM The effect of moderate alcohol ingestion on blood coagulation and fibrinolysis at rest and in response to exercise. $J$ Sports Sci 1999; 17: 513-20.

11. van de Wiel A, van Golde PM, Kraaijenhagen RJ, von dem Borne PA, Bouma BN, and Hart HC Acute inhibitory effect of alcohol on fibrinolysis. Eur J Clin Invest 2001; 31: $164-70$.

12. Olsen $\mathrm{H}$ and Osterud B Effects of ethanol on human blood fibrinolysis and coagulation. Alcohol Alcohol Suppl 1987; 1: 591-4.

13. Delahousse B, Maillot F, Gabriel I, Schellenberg F, Lamisse F, and Gruel Y Increased plasma fibrinolysis and tissue-type plasminogen activator/tissue-type plasminogen activator inhibitor ratios after ethanol withdrawal in chronic alcoholics. Blood Coagul Fibrinolysis 2001; 12: 59-66.

14. de Lange DW, Hijmering ML, Lorsheyd A, Scholman WL, Kraaijenhagen RJ, Akkerman JW, et al. Rapid intake of alcohol (binge drinking) inhibits platelet adhesion to fibrinogen under flow. Alcohol Clin Exp Res 2004; 28: 1562-8.

15. Kaufmann CR, Dwyer KM, Crews JD, Dols SJ, and Trask AL Usefulness of thrombelastography in assessment of trauma patient coagulation. J Trauma 1997; 42: 716-20; discussion 720-2. 
16. Wong CA, Liu S, and Glassenberg R Comparison of thrombelastography with common coagulation tests in preeclamptic and healthy parturients. Reg Anesth 1995; 20: $521-7$.

17. Essell JH, Martin TJ, Salinas J, Thompson JM, and Smith VC Comparison of thromboelastography to bleeding time and standard coagulation tests in patients after cardiopulmonary bypass. J Cardiothorac Vasc Anesth 1993; 7: 410-5.

18. Engstrom M, Reinstrup P, and Schott U An in vitro evaluation of standard rotational thromboelastography in monitoring of effects of recombinant factor VIIa on coagulopathy induced by hydroxy ethyl starch. BMC Blood Disord 2005; 5: 3.

19. Bowbrick VA, Mikhailidis DP, and Stansby G Influence of platelet count and activity on thromboelastography parameters. Platelets 2003; 14: 219-24.

20. Nielsen VG The detection of changes in heparin activity in the rabbit: a comparison of anti-xa activity, thrombelastography, activated partial thromboplastin time, and activated coagulation time. Anesth Analg 2002; 95: 1503-6, table of contents.

21. Goh KY, Tsoi WC, Feng CS, Wickham N, and Poon WS Haemostatic changes during surgery for primary brain tumours. J Neurol Neurosurg Psychiatry 1997; 63: 334-8.

22. Metcalf K Thrombelastograph monitoring: a clinical perspective. Nurse Anesth 1990; 1: $33-7$.

23. Caprini JA, Traverso CI, and Arcelus JI Perspectives on thromboelastography. Semin Thromb Hemost 1995; 21 Suppl 4: 91-3.

24. Hendriks HG, Meijer K, de Wolf JT, Porte RJ, Klompmaker IJ, Lip H, et al. Effects of recombinant activated factor VII on coagulation measured by thromboelastography in liver transplantation. Blood Coagul Fibrinolysis 2002; 13: 309-13. 
25. Murray DJ, Brosnahan WJ, Pennell B, Kapalanski D, Weiler JM, and Olson J Heparin detection by the activated coagulation time: a comparison of the sensitivity of coagulation tests and heparin assays. J Cardiothorac Vasc Anesth 1997; 11: 24-8.

26. Tuman KJ, Spiess BD, McCarthy RJ, and Ivankovich AD Effects of progressive blood loss on coagulation as measured by thrombelastography. Anesth Analg 1987; 66: 85663.

27. Engstrom M, Schott U, and Reinstrup P Acidosis impairs the coagulation - A thromboelastographic study. J Trauma 2005; In press.

28. Kettner SC, Sitzwohl C, Zimpfer M, Kozek SA, Holzer A, Spiss CK, et al. The effect of graded hypothermia (36 degrees C-32 degrees C) on hemostasis in anesthetized patients without surgical trauma. Anesth Analg 2003; 96: 1772-6, table of contents.

29. Stein SC, Young GS, Talucci RC, Greenbaum BH, and Ross SE Delayed brain injury after head trauma: significance of coagulopathy. Neurosurgery 1992; 30: 160-5.

30. Oertel M, Kelly DF, McArthur D, Boscardin WJ, Glenn TC, Lee JH, et al. Progressive hemorrhage after head trauma: predictors and consequences of the evolving injury. $J$ Neurosurg 2002; 96: 109-16.

31. Engstrom M, Romner B, Schalen W, and Reinstrup P Thrombocytopenia predicts progressive hemorrhage after head trauma. J Neurotrauma 2005; 22: 291-6.

32. Nguyen A, Packham MA, and Rand ML Effects of ethanol on platelet responses associated with adhesion to collagen. Thromb Res 1999; 95: 303-14.

33. Grenett HE, Aikens ML, Tabengwa EM, Davis GC, and Booyse FM Ethanol downregulates transcription of the PAI-1 gene in cultured human endothelial cells. Thromb Res 2000; 97: 247-55. 
34. Grenett HE, Aikens ML, Torres JA, Demissie S, Tabengwa EM, Davis GC, et al. Ethanol transcriptionally upregulates t-PA and u-PA gene expression in cultured human endothelial cells. Alcohol Clin Exp Res 1998; 22: 849-53.

35. Booyse FM, Aikens ML, and Grenett HE Endothelial cell fibrinolysis: transcriptional regulation of fibrinolytic protein gene expression (t-PA, u-PA, and PAI-1) by low alcohol. Alcohol Clin Exp Res 1999; 23: 1119-24.

36. Aikens ML, Grenett HE, Benza RL, Tabengwa EM, Davis GC, and Booyse FM Alcohol-induced upregulation of plasminogen activators and fibrinolytic activity in cultured human endothelial cells. Alcohol Clin Exp Res 1998; 22: 375-81. 


\section{FIGURE TEXTS}

\section{Figure 1A}

An original ROTEM registration of blood explaining the different parameters measured. Clot strength is found on the $\mathrm{Y}$ axis and time on the $\mathrm{X}$ axis. The clot strength is arbitrary and measured in $\mathrm{mm}$. Clotting Time (CT) is the time from initiation of clotting until the clot has gained a strength of $2 \mathrm{~mm}$ (thin black line).Clot Formation Time (CFT) is the time from clot strength $2 \mathrm{~mm}$ until clot strength $20 \mathrm{~mm}$ (black part of the curve). Alpha Angle is another measure of the rate of clot strengthening measuring the angle at which the clot strengthening takes place. Maximum Clot Firmness (MCF) is the maximum strength of the clot. Each square on the horizontal scale is equal to 10 minutes.

\section{Figure 1B}

An original ROTEM tracing showing Maximum Clot Firmness (MCF) and Lysis Index after $60 \mathrm{~min}$ (LI60). LI60 is the clot strength at 60 minutes as percentage of MCF. 


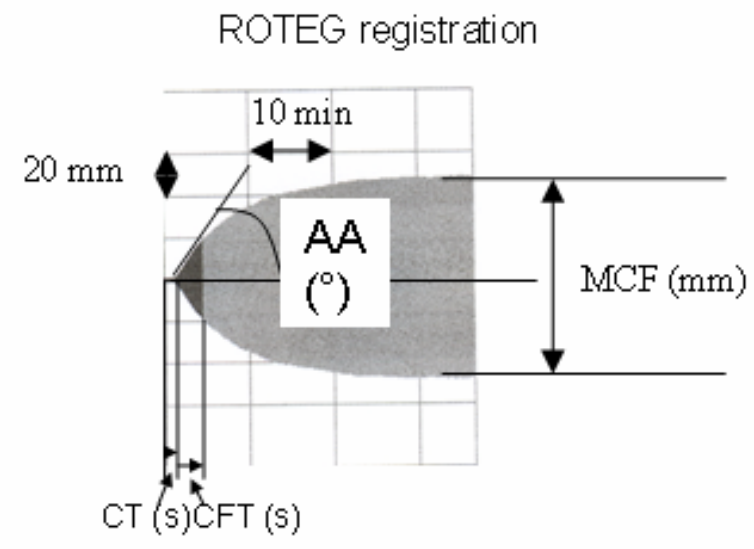

Figure $1 \mathrm{~A}$

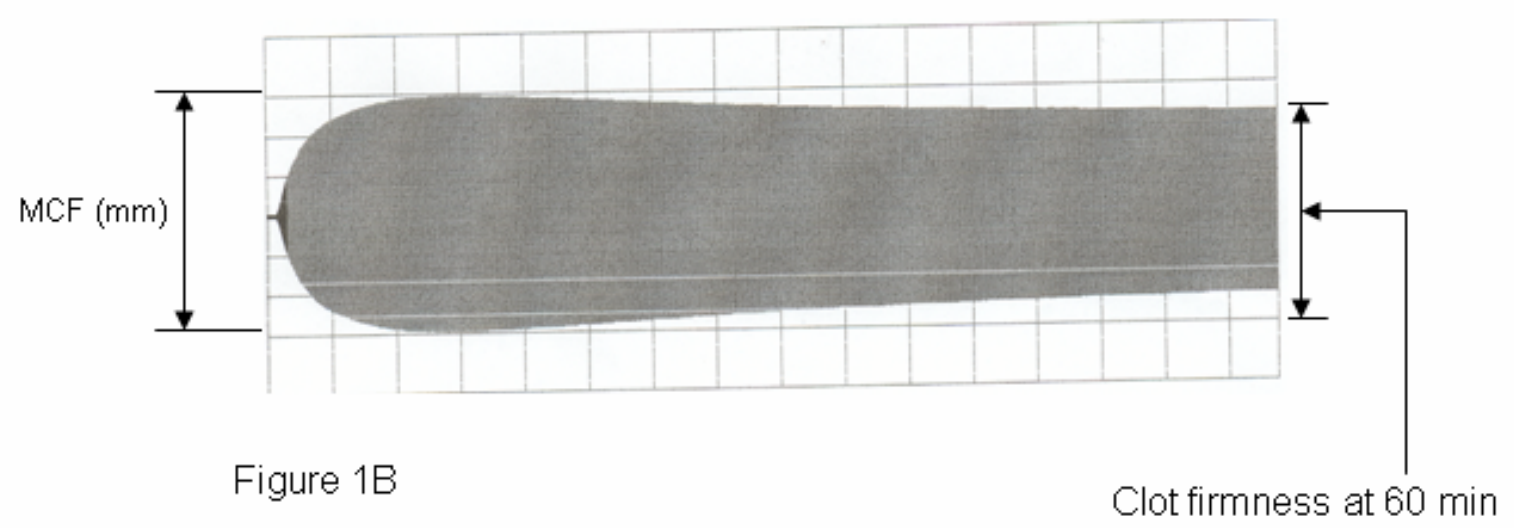




\section{Figure 2}

The figure shows the correlation between ethanol level and the Clot Formation Time (CFT).

The CFT is increasingly prolonged by increasing concentrations of ethanol $(p<0.000001$, $\mathrm{r}=0.91)$

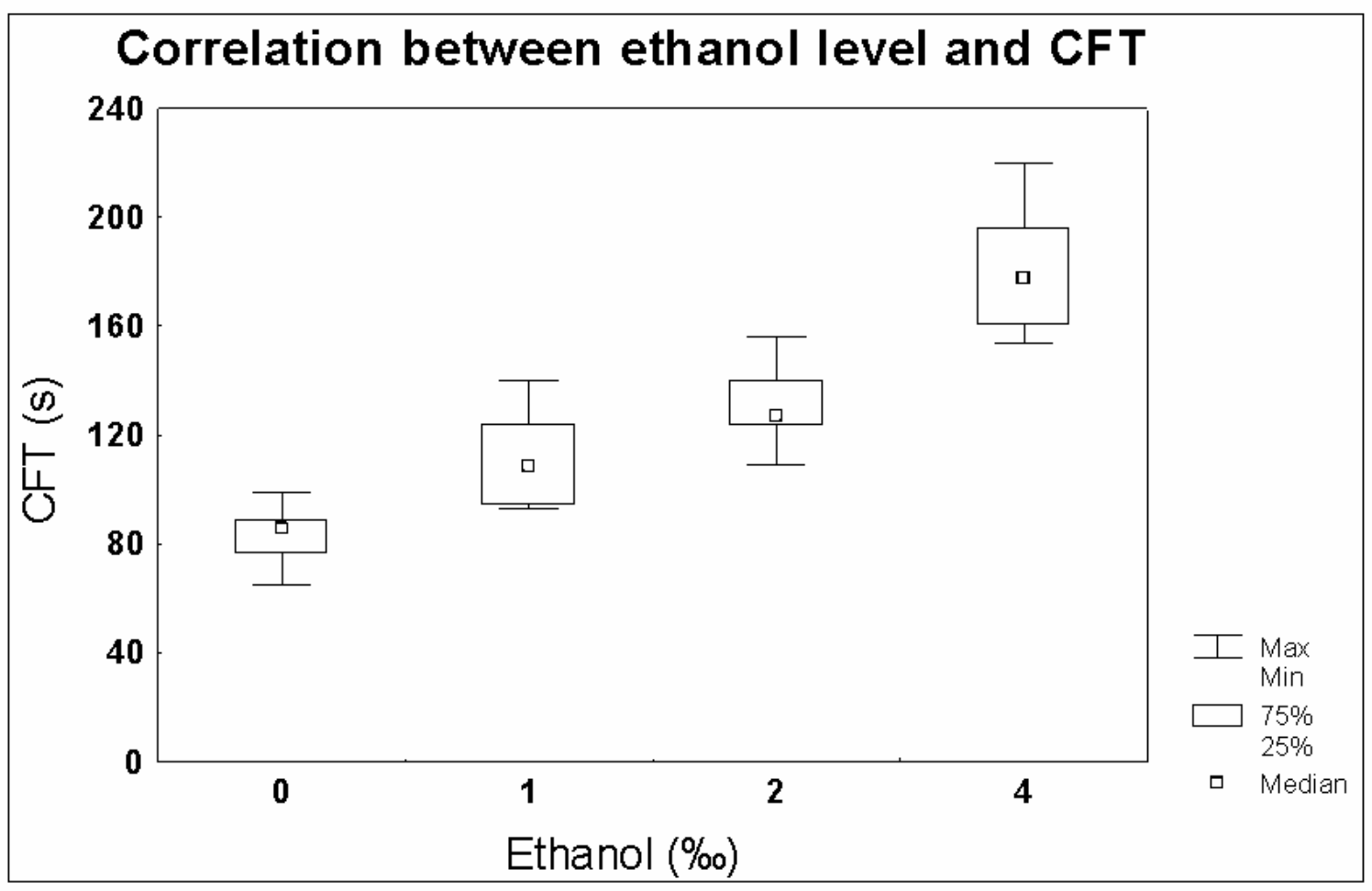

Figure 2 


\section{Figure 3A}

Original ROTEM tracing at an ethanol level of $0 \%$. The fibrinolysis without ethanol. Lysis can be readily seen as a narrowing ROTEM tracing after MCF has been passed.

\section{Figure 3B}

Original ROTEM tracing at an ethanol level of $1 \%$. Fibrinolysis is impaired as compared to figure $3 \mathrm{~A}$.

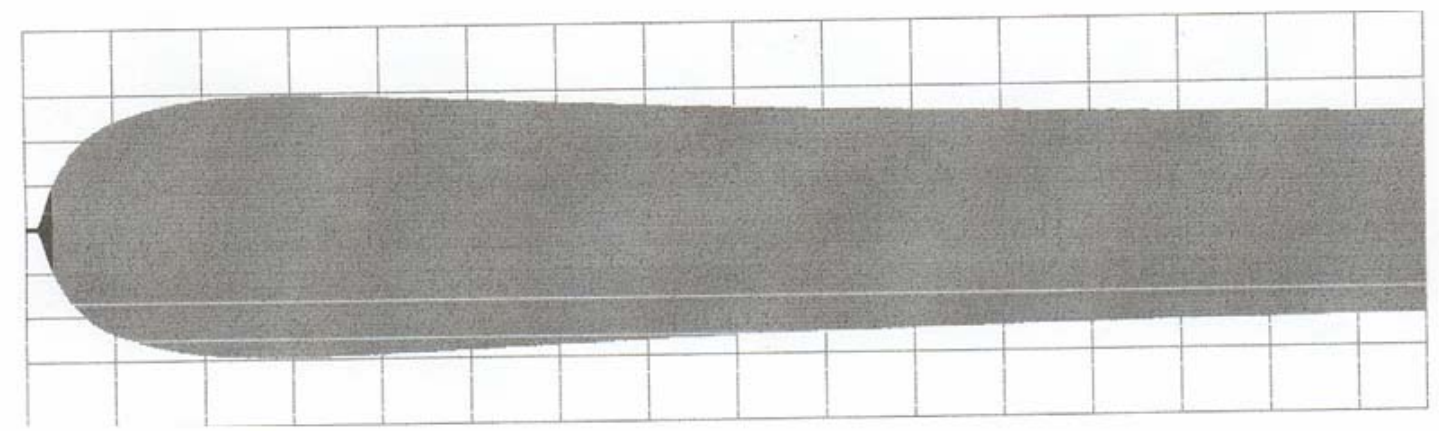

Figure 3A

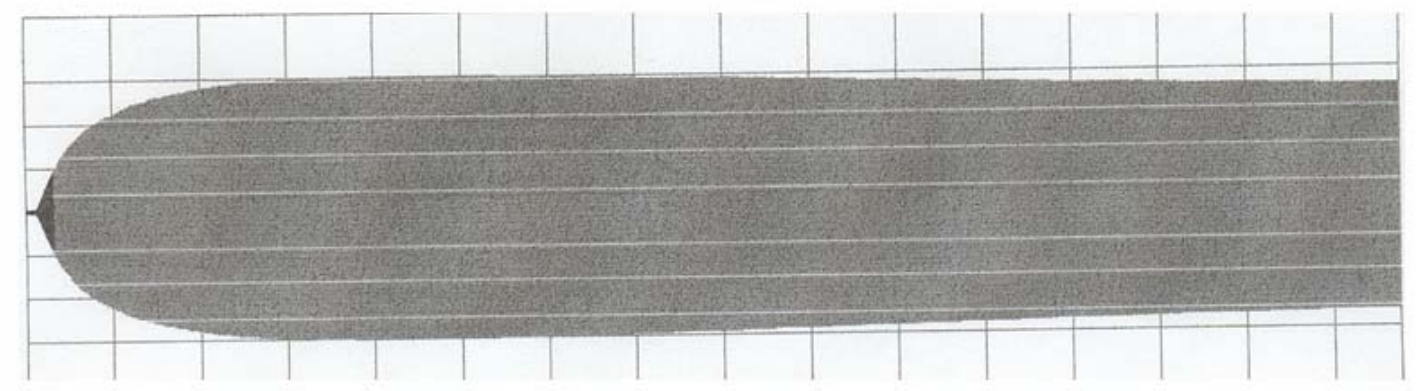

Figure 3B 